"Effects of Radiation on Materials: 18th Int1. Symp., ASTM STP 1325," eds. R. K. Nanstad, M. L. Hamilton, A. S. Kumar, and F. A. Garner, ASTM, 1997, in print.

\title{
Helium Behavior in Vanadium-Based Alloys Irradiated in the Dynamic Helium Charging Experiments
}

\section{CONF-960643--}

\author{
K. Fukumoto', H.M. Chung ${ }^{2}$, J. Gazda ${ }^{2}$, D.L. Smith ${ }^{2}$, and H. Matsui OCT 2 \\ 1. Institute for Materials Research, Tohoku University, Sendai 980-77, Japan. \\ 2. Argonne National Laboratory, Argonne, IL 60439, USA. \\ OSTI
}

Helium effect of neutron irradiated vanadium alloys, containing titanium, has been studied using Dynamic Helium Charging Experiment (DHCE) in FFTF. Cavity formation was observed only in pure vanadium irradiated at 430 to $600^{\circ} \mathrm{C}$ and in V-5Ti irradiated at $600^{\circ} \mathrm{C}$. No apparent cavity formation was obtained in V-3Ti-1Si and $\mathrm{V}-4 \mathrm{Cr}-4 \mathrm{Ti}$. The precipitation of titanium oxide in $\mathrm{V}-5 \mathrm{Ti}, \mathrm{V}-3 \mathrm{Ti}-1 \mathrm{Si}$ and $\mathrm{V}-4 \mathrm{Cr}-4 \mathrm{Ti}$ occurred in all irradiation conditions in this study and the precipitates of $\mathrm{Ti}_{5} \mathrm{Si}_{3}$ only appeared in $\mathrm{V}-3 \mathrm{Ti}-1 \mathrm{Si}$ irradiated at $600^{\circ} \mathrm{C}$ up to $15 \mathrm{dpa}$ with helium generation rate of $4 \mathrm{appmHe} / \mathrm{dpa}$. It is suggested that titanium oxide plays an important role for suppression of cavity formation and swelling from early stage of irradiation. Detail characterization of precipitates and $\mathrm{He}$ effect for neutron damages in vanadium alloys are discussed here.

\section{Introduction}

Extensive research of low activation vanadiumbase alloys for application in fusion reactor first wall and blanket structure has been conducted in the last decade because of the excellent combination of mechanical and physical properties before and after irradiation. One unresolved issue in the performance of these alloys, however, remains, i.e., the effect of simultaneous helium and neutron damage in fusion relevant irradiation condition (at a ratio of 4-5 appm helium/displacement per atom [dpa]) on void swelling. Some techniques tritium-trick[1], cyclotron-injection [2], and boron-doping[3] have been used to simulate the helium generation rate in fusion relevant condition. However the amount of helium was not consistent with pre-assumption and helium aggregated as helium bubbles on or near grain boundaries before neutron irradiation[4].

In the Dynamic Helium Charging Experiments, DHCE, the fusion-relevant helium-to-dpa ratio is simulated realistically by utilizing the transmutation of controlled amounts of $\mathrm{Li}$ and a predetermined amount of tritium-doped mother alloy immersed in $\mathrm{Li}+\mathrm{Li}[5]$. This report describes the results of microstructural characterization of vanadium alloy specimens irradiated in FFTF with the DHCE technique.

\section{Experimental Procedure}

The elemental composition of the vanadium alloys (pure V, V-5Ti, V-3Ti-1Si and V-4Cr-4Ti as ANL designation BL-19, 45, 46 and 47 , respectively) is listed in Table 1. Fabrication procedures of alloy ingots as well as annealed plates and sheets have been reported in previous works[6]. TEM disks punched from $0.3 \mathrm{~mm}$-thick cold-worked sheets, were annealed at $1050^{\circ} \mathrm{C}$. The only secondary phase present in the asannealed specimens was $\mathrm{Ti}(\mathrm{O}, \mathrm{N}, \mathrm{C})$, which is normally observed in titanium-containing vanadium alloys. The alloy specimens were irradiated in the Fast Flux Test Facility (FFTF), at 420,520 and $600^{\circ} \mathrm{C}$ to neutron fluence $(E>0.1 \mathrm{MeV})$ ranging from 0.37 to $6.4 \times 10^{23}$ $\mathrm{n} / \mathrm{m}^{2}, 15$ to 27 displacement per atom (dpa) estimated for pure vanadium. Helium in the alloy specimens was generated the decay of tritium transferred from the mother alloy via liquid lithium. Table 2 summarizes the actual damage and helium contents determined from. tensile and TEM specimens. Helium and tritium were determined by mass spectroscopy at Rockwell International Inc., Canoga Park, CA.

Table 1: The chemical composition of vanadium alloys in this work.

\begin{tabular}{|c|c|c|c|c|}
\hline \multirow{2}{*}{$\begin{array}{c}\text { Nominal Composition } \\
\text { (wt.\%) }\end{array}$} & \multicolumn{4}{|c|}{ Impurity Composition (wppm) } \\
\cline { 2 - 5 } & $\mathrm{O}$ & $\mathrm{N}$ & $\mathrm{C}$ & $\mathrm{Si}$ \\
\hline $\mathrm{V}$ & 1101 & 161 & 360 & - \\
\hline $\mathrm{V}-2.5 \mathrm{Ti}-0.9 \mathrm{Si}$ & 345 & 125 & 90 & 9000 \\
\hline $\mathrm{V}-4.6 \mathrm{Ti}$ & 300 & 53 & 85 & 160 \\
\hline $\mathrm{V}-4.1 \mathrm{CI}-4.3 \mathrm{Ti}$ & 350 & 220 & 200 & 870 \\
\hline
\end{tabular}

Table 2 : Summary of irradiation parameters of Dynamic Helium Charging Experiment and helium contents measured in V-4Cr-4Ti specimens. See in ref[6]

\begin{tabular}{|c|c|c|c|}
\hline $\begin{array}{c}\text { Irradiation } \\
\text { Temp; } \\
\left({ }^{\circ} \mathrm{C}\right)\end{array}$ & $\begin{array}{c}\text { Total Damage } \\
\text { for pure } \mathrm{V} \\
\text { (dpa) }\end{array}$ & $\begin{array}{c}\text { Helium } \\
\text { Content } \\
\text { (appm) }\end{array}$ & $\begin{array}{c}\text { Actual He/dpa } \\
\text { Ratio } \\
\text { (appm/dpa) }\end{array}$ \\
\hline 430 & 27 & $12.0 \pm 0.5$ & 0.39 \\
\hline 430 & 27 & $22.5 \pm 0.1$ & 0.73 \\
\hline 500 & 15 & $14.9 \pm 0.1$ & 0.83 \\
\hline
\end{tabular}

The retrieved TEM specimens were cleaned ultrasonically in alcohol prior to microstructural analysis. The examined TEM disks were not degassed. The irradiated specimens were jet-thinned for TEM observation in a solution of $20 \%$ sulfuric acid - $80 \%$ methanol maintained at $-25^{\circ} \mathrm{C}$. TEM observation was performed with JEOL-100CX-II in ANL operating at $100 \mathrm{kV}$.

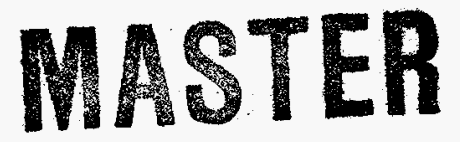




\section{DISCLAIMER}

This report was prepared as an account of work sponsored by an agency of the United States Government. Neither the United States Government nor any agency thereof, nor any of their employees, makes any warranty, express or implied, or assumes any legal liability or responsibility for the accuracy, completeness, or usefulness of any information, apparatus, product, or process disciosed, or represents that its use would not infringe privately owned rights. Reference herein to any specific commercial product, process, or service by trade name, trademark, manufacturer, or otherwise does not necessarily constitute or imply its endorsement, recommendation, or favoring by the United States Government or any agency thereof. The views and opinions of authors expressed herein do not necessarily state or reflect those of the United States Government or any agency thereof. 


\section{DISCLAIMIER}

Portions of this docmenent may be illegible in electronic image produets. Images are produced from the best available original document. 
Results

Pure Vanadium

Figure 1 shows the microstructure of neutron irradiated pure vanadium with DHCE method from 430 to $600^{\circ} \mathrm{C}$ with fluences from 15 to $28 \mathrm{dpa}$. Figure $1(\mathrm{a})$ shows a number of fine cavities in the matrix of the pure $V$ specimen irradiated at $430^{\circ} \mathrm{C}$ and Fig. I(d) shows larger ones irradiated at $600^{\circ} \mathrm{C}$. However, at $500^{\circ} \mathrm{C}$, no cavity was seen in the matrix of pure vanadium. On the other hand, dense and very fine dislocation loops or precipitates were formed in the matrix irradiated at $430^{\circ} \mathrm{C}$ and a low density of large dislocation loops are also observed. Above $500^{\circ} \mathrm{C}$, precipitates (mean size of their major axis is about 5 $\mathrm{nm}$ ) appeared and grew up with increasing irradiation temperature as shown in Fig. 1(b), (c) and (d). The irradiation-induced precipitates show fringes. Stacking fault energy in bcc structure is generally too high to form stacking fault with appreciable width. Figure 2 shows the dislocation images and diffraction pattern obtained from the same area. In Fig. 2(a), three types of platelet precipitates exist with edge-on configuration The foil normal of vanadium matrix is [111] so that the normal of platelets is type of [112] direction from the analysis of the orientation relationship. Other platelets which are inclined from [111] axis also have the indices of their normal, [112] direction. Thus, the habit plane of platelet precipitate is determined to be $\{112\}$. Figure 2(b) shows the selected area diffraction pattern and corresponding image of precipitates. The diffraction spots from precipitates appear in diffraction pattern. The $d$-spacing distance of them is $2.26 \AA$ and the type of crystal lattice may be of cubic type. In a recent work, the chemical analysis using EDS made clear that the precipitate consists of vanadium and light elements, $C$, $\mathrm{N}$ or $\mathrm{O}$. It is considered that the nature of the precipitate in pure vanadium is vanadium carbide or vanadium oxide from this work.

\section{V-5Ti}

$\mathrm{V}-(5-20) \mathrm{Ti}$ alloys have been recognized as highresistant materials against radiation-induced swelling. Understanding of the swelling resistance of these alloys may be helpful to develop vanadium alloys with excellent performance as fusion reactor structural materials. Figure 3 shows the microstructure of neutron irradiated V-5Ti alloys with DHCE technique. Figure 3 (a) shows the cavity image for $430^{\circ} \mathrm{C}$; the cavity in the matrix on the left, the cavity aggregation along a grain boundary on the right. The precipitate image for $430^{\circ} \mathrm{C}$ show at the bottom left part, and dense fine platelet precipitates inhomogeneously in the matrix. The preferential cavity formation on grain boundaries were observed, which have never been observed in $\mathrm{V}-\mathrm{Ti}$ alloys with conventional neutron irradiation producing negligible amount of helium[7]. However, the cavity formation was not observed at $600^{\circ} \mathrm{C}$ irradiation and large platelet precipitates were formed as shown in Fig. 2 (b) and (c) with a different helium generation rate. The precipitates are elongated along the [100] direction and grew up to $30 \mathrm{~nm}$. The reflection spot from the precipitates is close to the (110) reflection of the vanadium matrix and is aligned as a band along the [100] directions. No strain contrast around the precipitate can be seen, which suggests the lack of coherency with the vanadium matrix. EDS analysis was done to determine the chemical composition of the precipitates. From EDS analysis, the precipitates consist of titanium and light elements, i.e., $\mathrm{C}, \mathrm{N}$ or $\mathrm{O}$. These types of precipitate have been observed in a previous study[8] and their nature was determined using diffraction analysis using TEM and internal friction technique. Referring to and comparing with the previous work[8], this type of precipitate are considered to be titanium oxide, $\mathrm{Ti}_{2} \mathrm{O}$ or $\mathrm{TiO}_{\mathrm{x}}(\mathrm{x}<0.5)$ in particular.

\section{V-3Ti-1Si}

Small addition of silicon to vanadium alloys has been reported to give resistance to swelling under neutron irradiation[9]. Figure 4 shows the microstructure of neutron-irradiated V-3Ti-1Si with DHCE. At $430^{\circ} \mathrm{C}$, cavities were formed with extremely low density as shown in Fig. 4(a). Along with cavity formation, high density of fine precipitates was observed as in V-5Ti. With increasing irradiation temperature, cavities disappeared and the growth rate of planar precipitates rapidly increased as shown in Fig. 4; the irradiation temperature $\left({ }^{\circ} \mathrm{C}\right.$ ) and the helium generation rate (appmHe/dpa) was 500, 0.5(b), 600, 0.5 (c) and $600,4.2(\mathrm{~d})$; respectively. The planar precipitate in Fig. 4 (b-d) resemble one of $\mathrm{V}-5 \mathrm{Ti}$. At $600^{\circ} \mathrm{C}$ with 4.2 appmHe/dpa, however, different type of precipitates from titanium oxide appeared in the matrix. Figure 5 shows the bright field images and diffraction pattern of the precipitate in V-3Ti-1Si neutronirradiated at $600^{\circ} \mathrm{C}$ with 4.2 appmHe/dpa. Two types of precipitates were formed together in the same grain. The left one shows the titanium oxide as mentioned in the V-5Ti section. The right one, disk type precipitates have a diffraction pattern different from titanium oxide. The weak spots in Fig. 5 are from precipitates of which crystal structure has been determined hexagonal type, with the orientation relationship $[110]_{v} / /[1210]_{\text {precipitate, }}$ (111) $/ /(0001)_{\text {precipitate }}$ and the habit plane of $\{110\}$. The d-spacing of (1210) and (3630) of the precipitate is $6.62 \AA$ and $2.20 \AA$, respectively. The same type of precipitate has already been observed in V-3Ti-1Si irradiated at 600 and $800^{\circ} \mathrm{C}$ with a damage level of 15 and $17 \mathrm{dpa}$, respectively using the tritium-trick technique[10]. The nature of the precipitates has been determined to be titanium silicide by a detailed analysis The precipitate has been reported to be $\mathrm{Ti}_{5} \mathrm{Si}_{3}$ which has hexagonal structure[11] with a lattice constant of ao 
is $7.463 \AA$. Although There are some discrepancies still, but it is clear that the titanium silicides were formed only in $\mathrm{V}-3 \mathrm{Ti}-1 \mathrm{Si}$ irradiated at $600^{\circ} \mathrm{C}$.

$V-4 C r-4 T i$

$\mathrm{V}-\mathrm{Cr}-\mathrm{Ti}$ alloys are base alloy for candidate materials of fusion reactor structural materials. In the previous work $[6,12], \mathrm{V}-4 \mathrm{Cr}-4 \mathrm{Ti}$ alloy has shown excellent radiation-resistant properties under neutron irradiation with concurrent helium generation using the DHCE technique. Figure $6(a)$ to (c) show the microstructure of $\mathrm{V}-4 \mathrm{Cr}-4 \mathrm{Ti}$ irradiated at $430^{\circ} \mathrm{C}, 500^{\circ} \mathrm{C}$ and $600^{\circ} \mathrm{C}$, respectively. In Fig. $6(\mathrm{~b})$ and (c), the dark field images obtained using precipitate reflection are inserted. In this work, cavity was never observed in the alloy, $\mathrm{V}-4 \mathrm{Cr}-4 \mathrm{Ti}$, which is contrasted to the previous report[12] where cavities were observed around grain boundaries[12]. $\mathrm{V}-4 \mathrm{Cr}-4 \mathrm{Ti}$ had rather higher dislocation density than other alloys studied here. High density of precipitates are also observed and they grew up and the density increased with raising the irradiation temperature. However, the growth of precipitates was so much larger than in V-5Ti and V-3Ti-1Si. The nature of the precipitates is similar with those in V-5Ti and V3Ti-1Si observed in this study. Thus, it is conducted that the precipitates formed in neutron-irradiated $\mathrm{V}$ $4 \mathrm{Cr}-4 \mathrm{Ti}$ are titanium oxide, $\mathrm{Ti}_{2} \mathrm{O}$ or $\mathrm{TiO}_{\mathrm{x}}(\mathrm{x}<0.5)$.

\section{Discussion}

The swelling behavior of neutron-irradiated vanadium alloys has been reported by many workers. The precipitation induced by radiation damage plays an important role for the suppression and procession of radiation-induced swelling. In pure vanadium in this work, the cavity formation was seen at $430^{\circ} \mathrm{C}$ and $600^{\circ} \mathrm{C}$, while, no cavity was observed at $500^{\circ} \mathrm{C}$. On the other hand, precipitation of vanadium carbide or oxide occurred in all irradiation conditions. From table1, pure vanadium, ANL designation: BL-19 contains mush more impurity, carbon and oxygen than other pure vanadium used in many of the experiments reported so far. It has been reported that the cavity formation occurred at 500 or $520^{\circ} \mathrm{C}$ and a few dislocations and no precipitation were observed in FFTF or JOYO irradiation $[7,13]$. The reason why cavity formation were suppressed at $500^{\circ} \mathrm{C}$ in this study should be due to the precipitation providing effective sinks for point defects. It is considered that high density of precipitates act as neutral sink to trap the vacancy and interstitials, and the concentration of point defects are reduced leading to the suppression of cavity formation. In order to examine the mechanism of suppression of cavity formation, the information about the sink strength of these precipitates and the migration of point defects is required. At $600^{\circ} \mathrm{C}$, the precipitates were also produced but cavity formation was not suppressed. In this case, precipitates were coarsened and the density were decreased.

In vanadium alloys containing titanium, precipitates were formed in all irradiations conditions and cavity formation were only found in $\mathrm{V}-5 \mathrm{Ti}$ irradiated at $430^{\circ} \mathrm{C}$. The formation of void nuclei occurred so easily at low temperatures that the cavity formation only appeared at $430^{\circ} \mathrm{C}$. The nature of precipitates produced in $\mathrm{V}-5 \mathrm{Ti}, \mathrm{V}-3 \mathrm{Ti}-1 \mathrm{Si}$ and $\mathrm{V}-4 \mathrm{Cr}$ $4 \mathrm{Ti}$ is mainly $\mathrm{Ti}_{2} \mathrm{O}$, titanium oxide. $\mathrm{Ti}_{2} \mathrm{O}$ is not produced in unirradiated vanadium alloys and $\operatorname{Ti}(\mathrm{O}, \mathrm{N}$, C) with $\mathrm{NaCl}$ is only titanium oxide. The radiation induced precipitates, $\mathrm{Ti}_{2} \mathrm{O}$ should play a role as an effective sink for point defects and suppress the cavity formation and swelling provided the sink strength is significantly high. In the previous study[9], titanium silicide, $\mathrm{Ti}_{5} \mathrm{Si}_{3}$ has been reported to be playing an important role for suppression of swelling in $\mathrm{V}-4 \mathrm{Cr}-4 \mathrm{Ti}$ and other vanadium alloys. However, In this study, only precipitation of $\mathrm{Ti}_{5} \mathrm{Si}_{3}$ appears in $\mathrm{V}-3 \mathrm{Ti}-1 \mathrm{Si}$ irradiated at $600^{\circ} \mathrm{C}$. Titanium silicide, $\mathrm{Ti}_{5} \mathrm{Si}_{3}$, only appeared in vanadium alloys containing silicon. It is suggested that titanium oxide playing the major role in void suppression. The addition of titanium to vanadium alloys is more important to suppress radiation-induced swelling than silicon. On the other hand, it has been reported that the cavity formation occurred in V-3Ti$0.25 \mathrm{Si}$, but no cavity was formed in V-3Ti-0.5Si irradiated at $600^{\circ} \mathrm{C}$ in FFTF. This observation indicated that silicone addition to vanadium alloy is important to suppress the swelling. From the result by H.M. Chung[9], it is likely that V-3Ti-1Si has more effective self-healing property against swelling than $\mathrm{V}-\mathrm{Ti}$ alloys. We consider that titanium oxide is effective for the suppression of cavity formation from the early stage of irradiation. In the subsequent irradiation, $\mathrm{Ti}_{5} \mathrm{Si}_{3}$ precipitates are nucleated homogeneously and grow up slowly. Titanium oxides are coarsened significantly during irradiation and are longer able to influence the suppression of cavity formation. Therefore self-healing system against swelling in V-3Ti-1Si is caused by two step formation of precipitates, both titanium oxide and silicide under irradiation. We have to discuss further about which element is more effective for swelling suppression in vanadium alloys.

Only TEM observation of DHCE specimens was done in this experiments and the comparison with both DHCE specimens and $\mathrm{He}$ free specimens irradiated with neutron was not examined. For another experiment from ANL designation specimens, TEM observation of Japanese binary vanadium alloys has been performed and the comparison between DHCE specimen and Hefree irradiated specimen about swelling behavior has been done. Figure 7 shows the swelling of vanadium alloys for each alloys irradiated with DHCE and conventional neutron irradiation. Except for V-5Mo, the radiation induced cavity formation can't be seen in vanadium alloys. Moreover, $\mathrm{V}-5 \mathrm{Ti}$ and $\mathrm{V}-3 \mathrm{Ti}-1 \mathrm{Si}$ does 
not show the swelling with or without concurrent $\mathrm{He}$ implantation. Titanium atoms in solution in vanadium alloys work to suppress the cavity formation as trap for vacancies or impurity atoms during $\mathrm{He}$ free neutron irradiation. Addition of oversized solute atoms in metals, especially including titanium in vanadium, has been reported to suppress the swelling remarkably. During neutron irradiation with He implantation, only solute titanium atoms work no longer as effective sink for $\mathrm{He}$ atoms. In addition to the titanium atoms in solution, the precipitation of titanium oxide should be effective as trapping sites for $\mathrm{He}$ atoms and suppresses the cavity formation and reduce the radiation induced swelling.

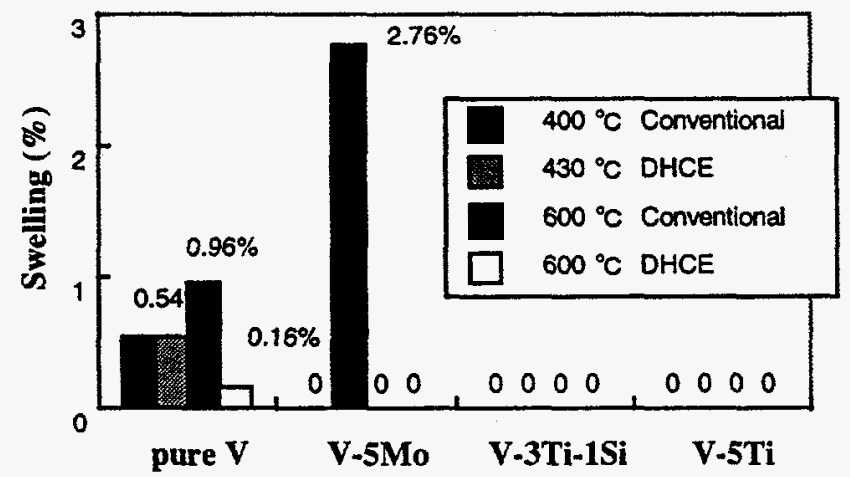

Figure 7 : The swelling of vanadium alloys for each alloys irradiated with DHCE and conventional neutron irradiation. These data were obtained by TEM observation of Japanese vanadium alloy specimens with or without DHCE technique.

\section{Conclusion}

No void appeared in pure $\mathrm{V}$ at $500^{\circ} \mathrm{C}$ irradiation. The high density of vanadium carbide or vanadium oxide appears to act as sink for point defects and prevents the formation of void nuclei. Precipitates of $\mathrm{Ti}_{2} \mathrm{O}$ were observed in all $\mathrm{Ti}$-containing vanadium alloys, i.e., V-5Ti, V-3Ti and V-4Cr-4Ti. Since $\mathrm{Ti}_{5} \mathrm{Si}_{3}$ was observed only in $\mathrm{V}-3 \mathrm{Ti}-1 \mathrm{Si}$ at $600^{\circ} \mathrm{C}$, while swelling suppression was observed in all conditions, titanium silicide is not considered essential for swelling suppression from the early stage of irradiation. Void swelling of vanadium alloys was not remarkable when irradiated under concurrent helium generation using DHCE. Swelling suppression by titanium in solution, alone may be sufficient in He-free conditions, while under fusion-relevant $\mathrm{He}$ generation, He trapping by fine precipitates, e.g. $\mathrm{Ti}_{2} \mathrm{O}$, is effective for swelling reduction.

\section{Acknowledgment}

This study was supported in part by the Japan-USA Fusion Cooperation in "JUPITER" program sponsored by Monbusho, the Japanese Ministry of Education, Science and Culture. This author, K.F, is grateful in particular to $H$. Chung, L. Nowicki and J. Gazda for helpful suggestion, fruitful discussion and more.

\section{Reference}

[1] D.N. Braski and D.W. Ramey; ASTM-STP 870 (1985) 1211-1224.

[2] J.M. Vitek, D.N. Braski, and J.A. Horak; J. Nucl. Mater., 141-143 (1986) 982.

[3] L.L. Horton and K.Farrell; J. Nucl. Mater., 122-123 (1984) 687.

[4] M. Tanaka and H. Matsui; Material Transaction, JIM, 34 (1993) 1083.

[5] H. Tsai, H. M. Chung, B. A. Loomis, and D. L. Smith; DOE/ER-0313/15 (1994), p. 247.

[6] H. M. Chung, B. A. Loomis, L. Nowicki, and D. L. Smith; DOE/ER-0313/17 (1994), p. 198.

[7] H. Nakajima, S. Yoshida, Y. Kohno and H. Matsui; J. Nucl. Mater., 191-194 (1992) 952-956

[8] R. Carlander, S.D. Harkness and T. Santhanam; ASTM-STP 529 (1973) 399-414.

[9] H.M. Chung, B.A. Loomis, L. Nowicki and etc.; DOE/ER-0313/15 (1993) 223.

[10] K. Fukumoto, Y. Candra and H. Matsui, unpublished work

[11] JCPDS, Powder Diffraction Files inorganic materials, 29-1362 (1987)

[12] H. M. Chung, L. Nowicki, J.Gazda and etc; DOE/ER-0313/17 (1994) 211.

[13] K. Fukumoto, S. Yoshida and H. Matsui, unpublished work.

\footnotetext{
The submitted manuscript has been created by the University of Chicago as Operator of Argonne National Laboratory ("Argonne") under Contract No. W-31-109-ENG-38 with the U.S. Department of Energy. The U.S Government retains for itself, and others act ing on its behalf, a paid-up, nonexclusive, irrevocable worldwide license in said article to reproduce, prepare derivative works, distribute copies to the public, and perform publicly and display publicly, by or on behalf of the Government
} 


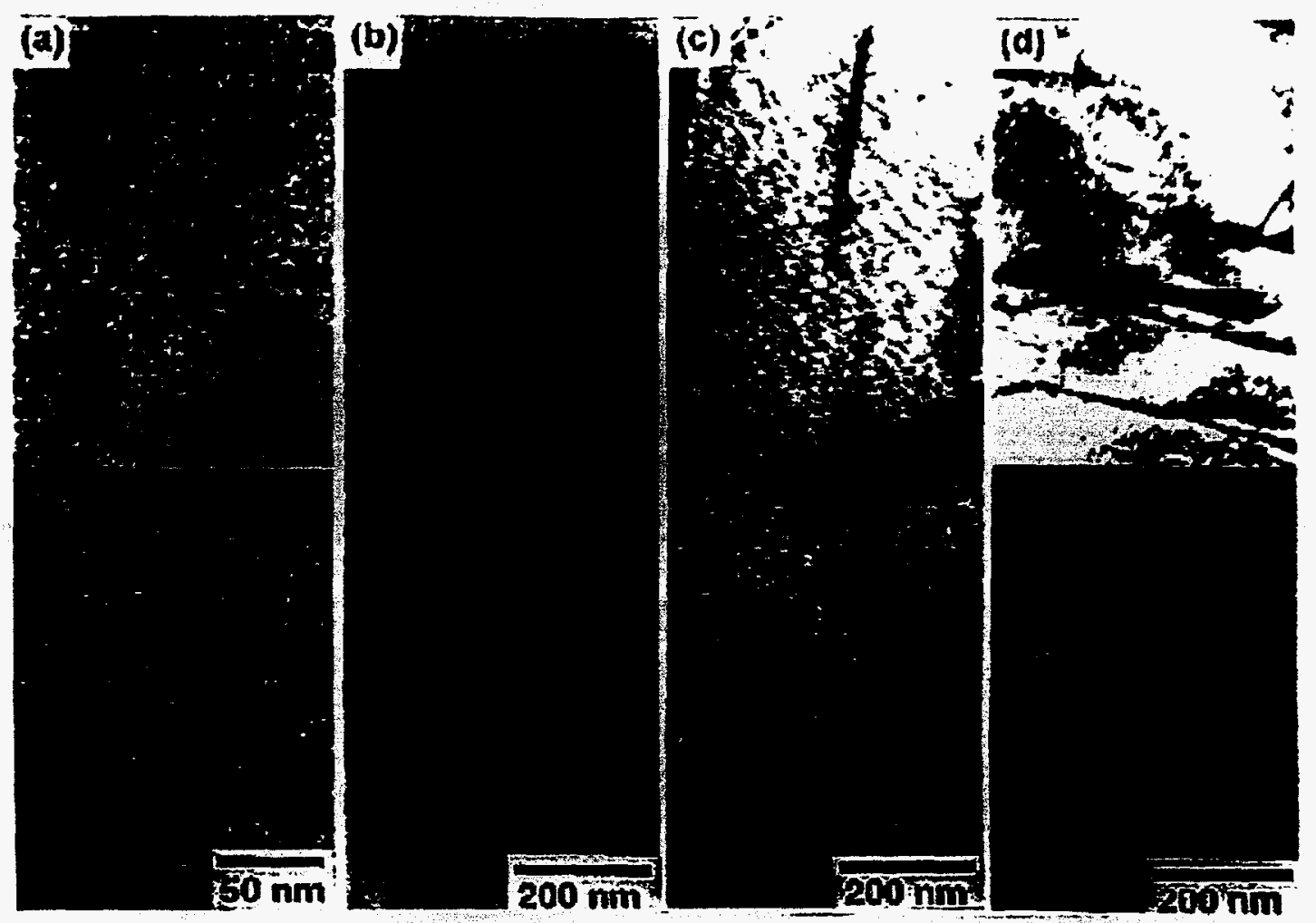

Figure 1 : The microstructure of neutron irradiated pure vanadium with DHCE method at from 430 to $600^{\circ} \mathrm{C}$ with fluences of 15 to $27 \mathrm{dpa}$. (a) dislocation and void images at $430^{\circ} \mathrm{C}$, (b) dislocation images at $500^{\circ} \mathrm{C}$, (c) dislocation images at $600^{\circ} \mathrm{C}$ with He generation rate of $0.5 \mathrm{He}$ appm/dpa and (d) dislocation and void images at $600^{\circ} \mathrm{C}$ with He generation rate of $4.2 \mathrm{He}$ appm/dpa

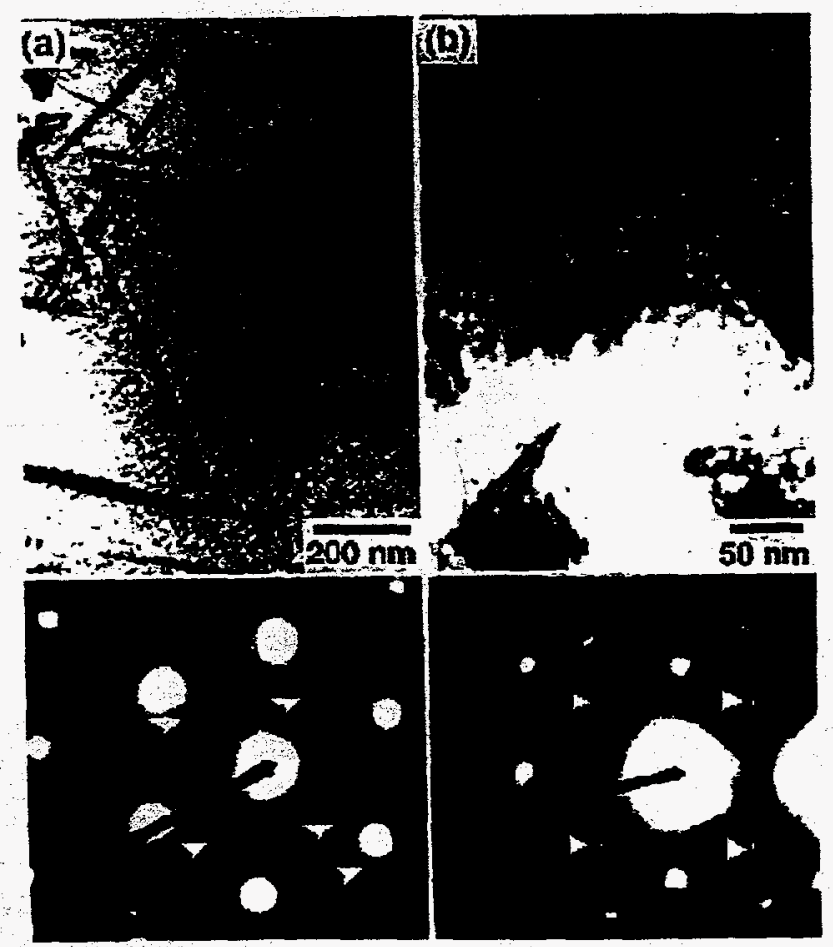

Figure $2:$ (a) the precipitate image near [111] direction and(b) one near [110] direction. The selected area diffraction patterns are shown at bottom part respectively and white triangles mark the reflection spot from precipitates. 


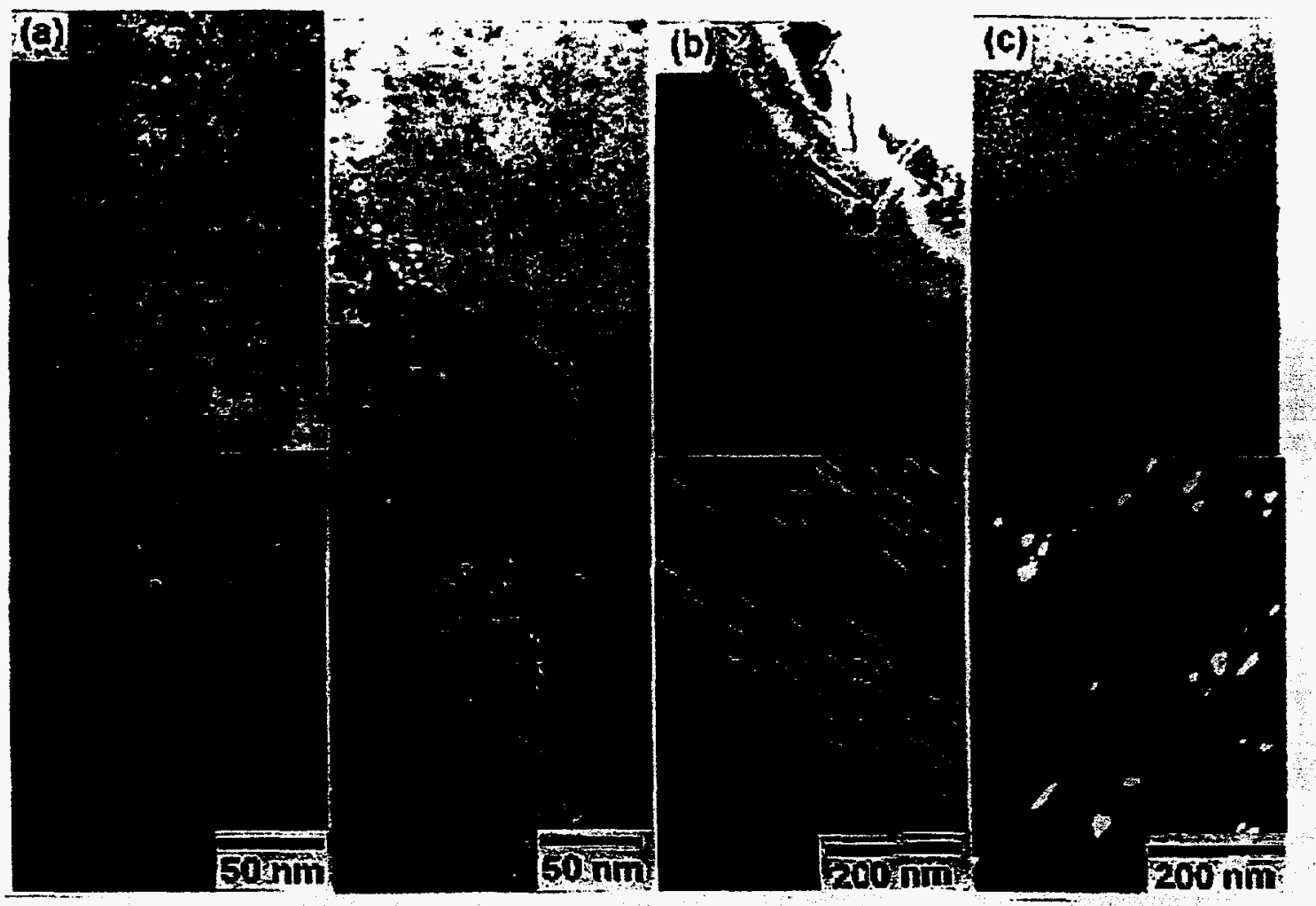

Figure 3 : The microstructure V-5Ti irradiated at from 430 to $600^{\circ} \mathrm{C}$ with fluences of 15 to $27 \mathrm{dpa}$ using DHCE method. (a) dislocation and void images, and the void image around grain boundary at $430^{\circ} \mathrm{C}$, (b) dislocation and void images at $500^{\circ} \mathrm{C}$, (c) dislocation and void images at $600^{\circ} \mathrm{C}$ with He generation rate of 4.2 He appm/dpa

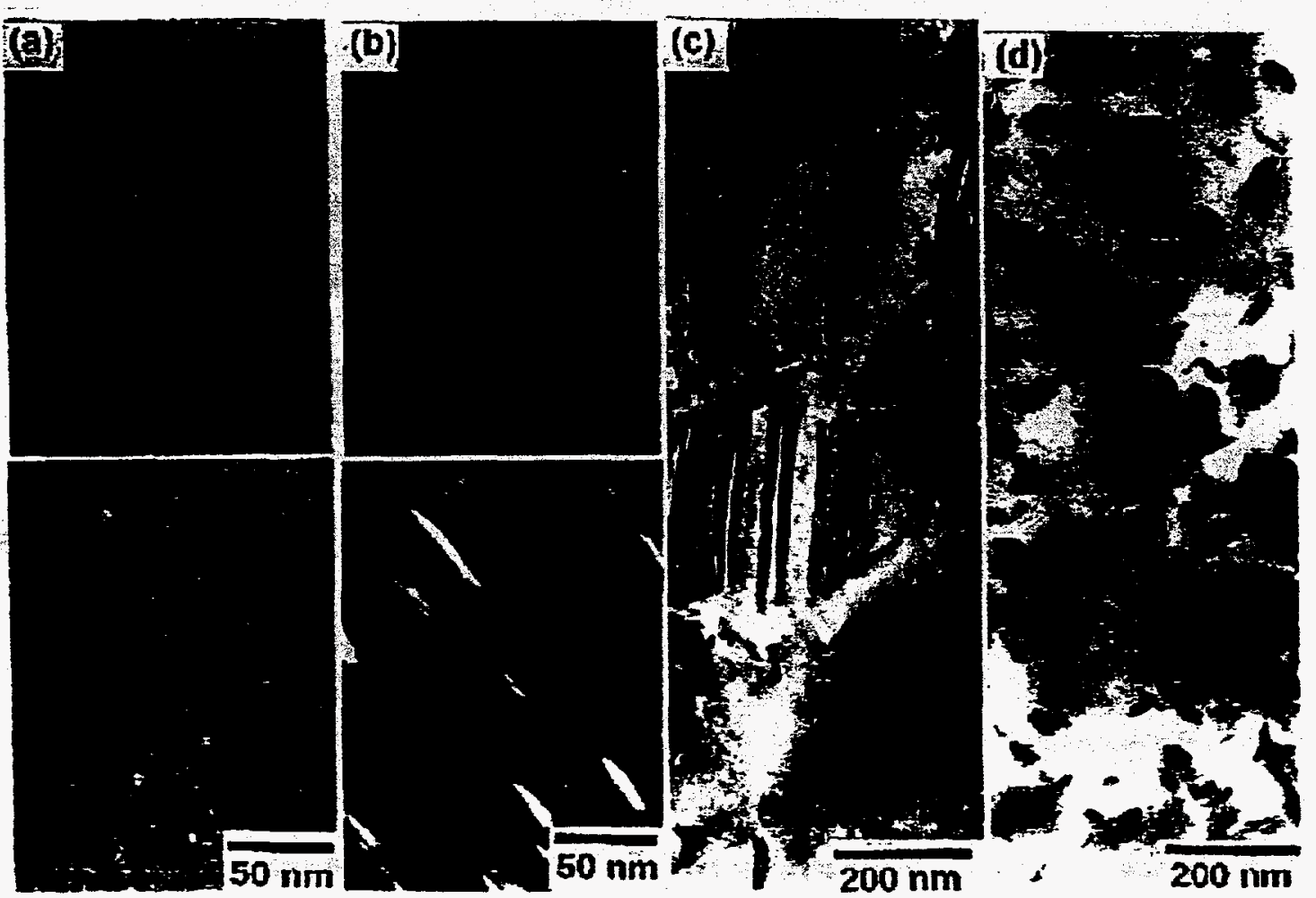

Figure 4 : The microstructure of V-3Ti-1Si al from $43010600^{\circ} \mathrm{C}$ with damage level of 15 to $27 \mathrm{dpa}$ using DHCE. (a) dislocation and void images at $430^{\circ} \mathrm{C}$. (b) dislocation images at $500^{\circ} \mathrm{C}$. (c) dislocation image at $600^{\circ} \mathrm{C}$ with $\mathrm{He}$ gencration rate of $0.5 \mathrm{He}$ arpm/dpa and (d) dislucation image at $600^{\circ} \mathrm{C}$ with He generation rate of 4.2 He annmon/dpa 


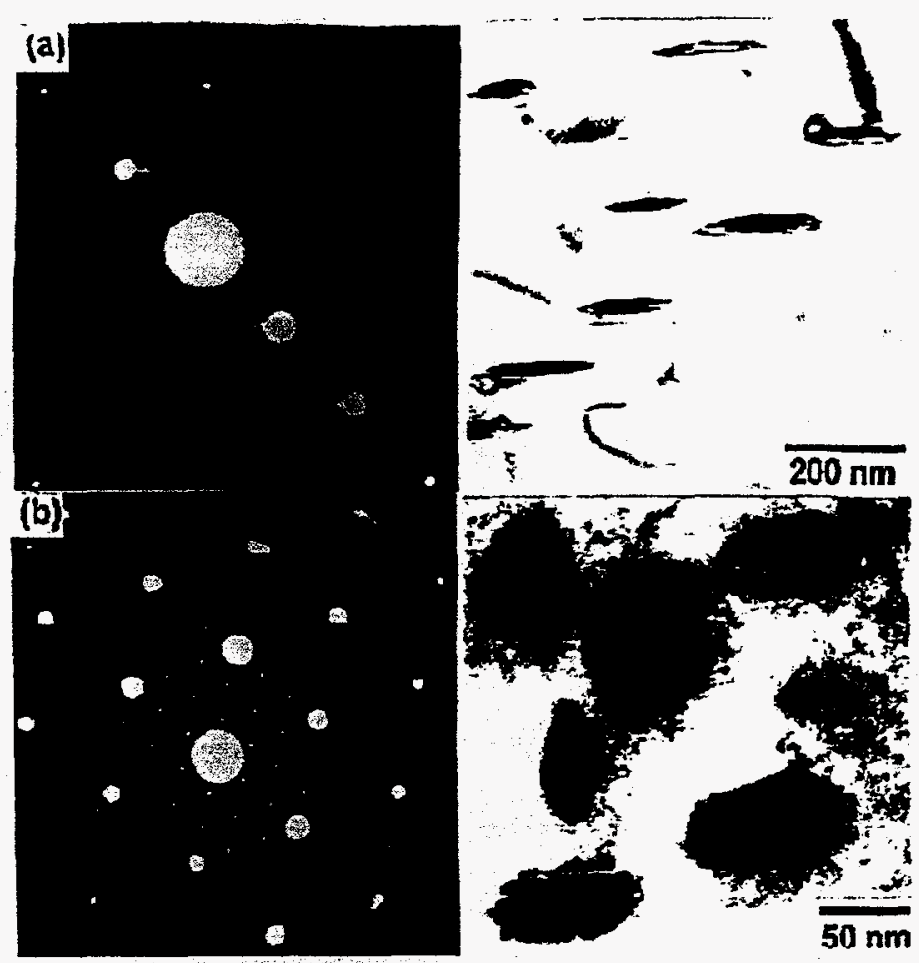

Figure 5 :The selected area diffraction patterns and the precipitates in V-3Ti-1Si at from $600{ }^{\circ} \mathrm{C}$ with $\mathrm{He}$ generation rate of $4.2 \mathrm{He}$ appm/dpa. (a) SADP was obtained near [001] direction. Same type of diffraction pattern with V-5Ti in fig.4. The nature of precipitates should be $\mathrm{Ti}_{2} \mathrm{O}$. (b) SADP was obtained close to [111] direction. You can see the weak spot occurred from precipitates.
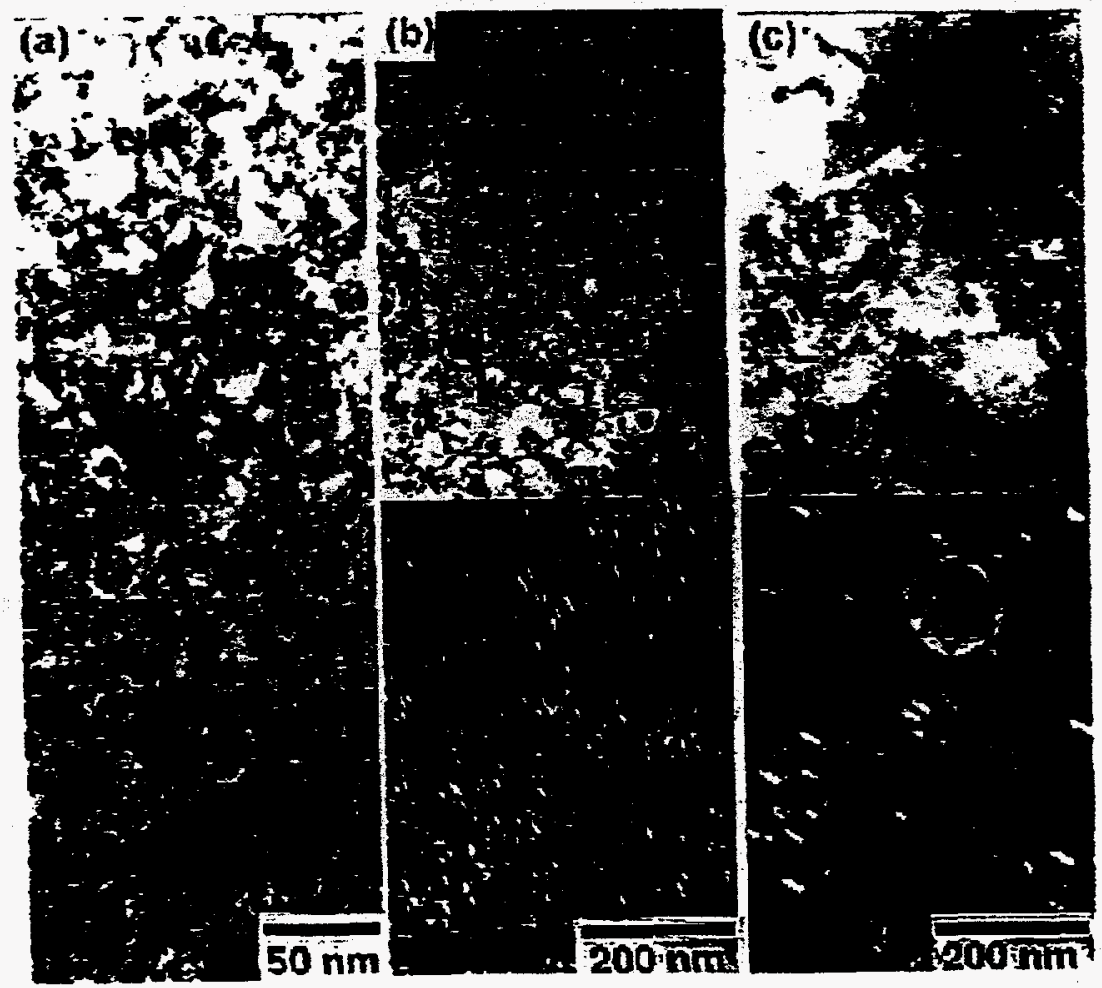

Figure 6 : The microstructure of $\mathrm{V}-4 \mathrm{Cr}-4 \mathrm{Ti}$ at from 430 to $600{ }^{\circ} \mathrm{C}$ with damage level of 15 to $27 \mathrm{dpa}$ using DHCE. (a) dislocation image at $430^{\circ} \mathrm{C}$, (b) $\mathrm{BF}$ dislocation and WBDF precipitate images at $500^{\circ} \mathrm{C}$, (c) BF dislocation and WBDF precipitate images at $600^{\circ} \mathrm{C}$. 